\title{
Application of Chemometrics for the simultaneous estimation of stigmasterol and $\beta$-sitosterol in Manasamitra Vatakam-an ayurvedic herbomineral formulation using HPLC-PDA method
}

\author{
Srikalyani Vemuri ${ }^{1}$, Mohan Kumar Ramasamy ${ }^{1}$, Pandiyan Rajakanu ${ }^{1}$, Rajappan Chandra Satish Kumar ${ }^{2}$, Ilango Kalliappan ${ }^{1,3^{*}}$ \\ ${ }^{1}$ Division of Analytical Chemistry, Interdisciplinary Institute of Indian System of Medicine (IIISM), SRM Institute of Science and Technology, Kattanku- \\ lathur-603 203, Kancheepuram (Dt), Tamil Nadu, India. \\ ${ }^{2}$ Clinical Trial and Research Unit (Metabolic Ward), Interdisciplinary Institute of Indian System of Medicine (IIISM), SRM Institute of Science and Tech- \\ nology, Kattankulathur-603 203, Kancheepuram (Dt), Tamil Nadu, India. \\ ${ }^{3}$ Department of Pharmaceutical Chemistry, SRM College of Pharmacy, SRM Institute of Science and Technology, Kattankulathur-603 203, Kancheepuram \\ (Dt), Tamil Nadu, India.
}

\section{ARTICLE INFO \\ Article history: \\ Received on: 08/05/2018 \\ Accepted on: 15/06/2018 \\ Available online: 30/07/2018}

\section{Key words:}

Chemometrics, Manasamitra

vatakam, RP HPLC,

Stigmasterol, $\beta$-sitosterol.

\begin{tabular}{l}
\hline ABSTRACT \\
\hline A new research method has been developed to approach multiresponse optimization for simultaneously optimizing \\
a large number of experimental factors. LC Chromatogram was optimized using Phenomenex RP $\mathrm{C}_{18}$ column $(250 \mathrm{x}$ \\
$4.6 \mathrm{~mm} ; 5 \mu \mathrm{m})$; mobile phase was surged at isocratic mode with a flow of $1.0 \mathrm{~mL} / \mathrm{min}$ using methanol and acetonitrile \\
$(95: 5 \% \mathrm{v} / \mathrm{v})$ at the detection max of $208 \mathrm{~nm}$ with the retention time of 16.3 and $18.1 \mathrm{~min}$ for Stigmasterol and \\
$\beta-$ Sitosterol respectively. Amount of Stigmasterol and $\beta$-Sitosterol was quantified and found to be 51.0 and $56.3 \mu \mathrm{g} /$ \\
$\mathrm{mg}$ respectively. The $\mathrm{r}^{2}$ value of 0.9971 and 0.9960 was found in the linear range of $80-130 \mu \mathrm{g} / \mathrm{mL}$ for Stigmasterol \\
and $\beta$-Sitosterol respectively. LOD and LOQ were $6.951,21.063 \mu \mathrm{g} / \mathrm{mL}$ and $6.048,18.328 \mu \mathrm{g} / \mathrm{mL}$ for Stigmasterol \\
and $\beta$-Sitosterol respectively. The relative standard deviation for the system and the method precision were found to be \\
$0.94 \%, 0.40 \%$ and $1.51 \%, 1.1 \%(\leq 2 \%)$ for stigmasterol and $\beta$-Sitosterol. Recovery studies were performed and found \\
in the range of $95-105 \%$ indicates the accuracy of the developed method. The developed chromatographic method is \\
the first report for the concurrent estimation of Stigmasterol and $\beta$-Sitosterol in Manasamitra Vatakam.
\end{tabular}

\section{INTRODUCTION}

$\mathrm{ICH} \mathrm{Q}_{8}(\mathrm{R})$ defines $\mathrm{QbD}$ approach as a "systematic commence for the development that begins with predefined objectives which conspicuous on the product, process understanding, and process control based on scientific attributes and quality risk management" (Pande et al., 2017).

Analytical methods are widely used in pharmaceutical development for divergent formulations of all categories which involves elution of active analytes and its separation with minimal resolution criteria (Sivakumar et al., 2007). Optimization of a

\footnotetext{
"Corresponding Author Ilango Kalliappan, Division of Analytical Chemistry, Interdisciplinary Institute of Indian System of Medicine (IIISM), SRM Institute of Science and Technology, Kattankulathur-603 203, Kancheepuram (Dt), Tamil Nadu.E-mail: ilangok67@gmail.com
}

single response with varying all the factors at a single approach, the chemometric analysis makes the best choice of separation (Mannemala et al., 2016), which helps in hasting the method development and extensively explains the chromatographic nature of the eluent. The different approaches to chemometric analysis include the pareto-optimality, path of steepest ascent, Derringer's desirability function and coerce acceleration of the procedure. The alley of gradient ascent can be exerted when the obtained responses are linear (Sivakumar et al., 2007).

The potent therapeutic agents are prepared from the traditional plants where herbal drugs and the chemical constituents from the plants form the major traditional claim in Ayurvedic, homeopathic, naturopathic and other medicine systems (Benzie et al., 2011). Due to the extensive and unknown side effects of allopathic systems, the herbal drug manufacturers have become relatively more as they are obtained from the natural origin 
which is less toxic reactions. Polyherbal formulations (PHF) have become the test of time, whereas the vast utilization of herbs has driven the hostile approach. PHF has better acceptability and compatibility than allopathic formulations, upon selection of high dose, the efficacy and safety increases and the adverse effects can be minimized. Traditional medicine provides an important health care service comparatively to allopathic medicine. In the global market of all the available medical formulation, $25 \%$ of the potent drugs are been synthesized and prescribed are from plants of higher therapeutic use (Sahoo et al., 2010).

India is rich in ethnic diversity and well-practiced knowledge in herbal medicines. Many classical ayurvedic formulations were texted in most of the contexts like Charakasamhita, Sahasrayogam, and Susrutasamhita. Manasamitra Vatakam (MMV), texted in Sahasrayogam (Krishna Kumar, 2008) a classical Ayurvedic polyherbal formulation available in the market as tablet dosage form is officially texted in Sahasrayogam, "Kerala Ayurvedic Pharmacopeia" used for the treatment of convulsions, stress, anxiolytic and depression disorders. It helps in providing the treatment for Generalized Anxiety Disorder (GAD) and depression on prolonging usage of the drug. MMV is also a powerful memory enhancer showing its overall therapeutic effects on the central nervous system (Goldberg et al., 2013). The major therapeutic indications include schizophrenia post-traumatic stress disorder, amnesia, Alzheimer's and cardiac arrhythmia due to anxiety. Literature survey reveals that MMV has the neuroprotective and antioxidant properties (Thirunavukkarasu et al., 2013).

Phytosterols comprise several bioactive properties like deprivation of cholesterol levels, regulating the LDL levels, inhibiting the tumor growth (Naiyer et al., 2017). Literature review explores that the inclusion of phytosterols in the diet can prevent and reduce the cancerous growth. The commonly occurring phytosterols in the diet are stigmasterol, $\beta$-sitosterol, and campesterol (Scholz et al., 2015). In the extent to the analytical applications, few chromatographic methods were available for the simultaneous estimation of phytosterols in various herbal formulations (Sandhiya et al., 2015; Nair et al., 2006; Careri et $a l ., 2001)$, HPLTC method validation of stigmasterol in the leaf and stem of Bryophyllum pinntum (Anjoo et al., 2015). There is no scientific method available to quantify any of the chemical constituents present in MMV. Hence an attempt was made to quantify phytosterols present in the formulation and validation as per ICH Q2b guidelines.

\section{MATERIALS AND METHODS}

\section{Experimental conditions}

\section{HPLC Instrumentation}

The samples were analyzed using HPLC Shimadzu Prominence model comprising of LC20AD binary solvent delivery module, SPD M20A PDA detector, a Rheodyne injector (model 7125, USA) valve fitted with a $20 \mu$ l loop, CT0-20A Column oven. The system was controlled with the controller module equipped with CBM-20A Communications Bus Module and the data acquisition was set using the Lab solutions software (7.1 Version). Separation and quantification were done on Phenomenex $\mathrm{C}_{18}$ column at the wavelength maximum of $208 \mathrm{~nm}$.
Design Expert was extensively used for the Chemometric measures, factorial analysis, Perturbation plots and desirability function calculations using 11.0 version and the MS Excel 2010 was used for the data analysis.

\section{Materials}

Stigmasterol $(99 \% \mathrm{w} / \mathrm{w})$ and $\beta$-sitosterol, depicted in Fig. 1 were purchased from M/S Natural Remedies, Bangalore, India. HPLC grade methanol and acetonitrile were used for the analyses. The mobile phase was vacuum filtered with a $0.45 \mu \mathrm{m}$ membrane filter. MMV was prescribed by the ayurvedic physician and was procured from the Ayurvedic pharmacy. The MMV used for the analysis further was manufactured by Kottakal.

\section{ANALYTICAL PROCEDURES}

\section{Preparation of standard stock solution}

The standard with the concentration of $200 \mu \mathrm{g} / \mathrm{mL}$ using methanol as a diluent was prepared for the construction of calibration curve for stigmasterol and $\beta$-sitosterol, the working standard solution was prepared in the linear range of $80-130 \mu \mathrm{g} /$ $\mathrm{mL}$. Both the stock and working standard solutions were stored in the refrigerator and protected from sunlight. The working standards were freshly prepared on the day of validation. The calibration curve reported was taken against peak area vs. concentration $(\mu \mathrm{g} /$ $\mathrm{mL}$ ) of the analyte.

\section{Preparation of sample solution}

Accurately weighed about twenty tablets and evenly powdered, from which weighed and transferred $1 \mathrm{~g}$ of powder into a $10 \mathrm{~mL}$ standard flask. $5 \mathrm{ml}$ of methanol as a diluent was added and complete extraction was exerted by sonication for about 30 min and made to the mark with the diluent. The sample matrix prepared was then subjected to prior filtration with Whatman filter paper and further filtration was done with $0.2 \mu \mathrm{m}$ membrane filter and the filtered solution was injected with a volume of $20 \mu \mathrm{l}$ for LC analysis.

\section{Chromatographic parameters}

The optimized chromatographic measures performed indulges the eluent composition of $\mathrm{MeOH}$ and $\mathrm{ACN}$ in the quotient of $95: 5 \% \mathrm{v} / \mathrm{v}$ with a flow rate of $1.0 \mathrm{~mL} \mathrm{~min}^{-1}$ and degassed the mobile phase for 15 min using ultrasonicator. Phenomenex $\mathrm{C}_{18}$ column was used as stationary phase. All the determinations were done under ambient temperature conditions $\left(25 \pm 2{ }^{\circ} \mathrm{C}\right)$ with an injection volume of $20 \mu \mathrm{L}$ at the detection speck of $208 \mathrm{~nm}$. The chromatographic conditions were maintained at an ambient temperature.

\section{RESULTS}

\section{Liquid chromatographic method optimization}

Central composite design (CCD) was initiated for the better optimization of the method and understanding the interactions for the factors selected to identify the chromatographic behavior of the elutes (Bezerra et al., 2008). The selection of key factors for optimization was based on preliminary experiments (Wang et al., 2006; Sivakumar et al., 2007). The chromatographic 
optimization includes the factors like wavelength (A), \% $\mathrm{MeOH}$ concentration $(B)$ and flow rate $(C)$. The selected variables range was diversified in the array of wavelength varied from 206 to 210 $\mathrm{nm}, \mathrm{MeOH}$ concentration was varied from 92 to $98 \% \mathrm{v} / \mathrm{v}$ and flow rate from 0.8 to $1.2 \mathrm{ml} \mathrm{min}{ }^{-1}$. For the proper optimization of the method under varied conditions, "the responses which highly alter the chromatographic nature were selected and identified are a resolution between the stigmasterol and $\beta$-sitosterol $\left(\mathrm{R}_{1}\right)$, retention time of stigmasterol and $\beta$-sitosterol $\left(R_{2} \& R_{3}\right)$ and peak ratio of stigmasterol $\left(\mathrm{R}_{4}\right)$ '”

Table 1: Central composite rotatable design (CCD) coupled with fractional factorial design and responses.

\begin{tabular}{|c|c|c|c|c|c|c|c|c|}
\hline \multirow{2}{*}{ Standard } & \multirow{2}{*}{ Space Type } & \multicolumn{3}{|c|}{ Factors } & \multicolumn{4}{|c|}{ Responses } \\
\hline & & $\mathbf{A}$ & B & C & $\mathbf{R}_{1}$ & $\mathbf{R}_{2}$ & $\mathbf{R}_{3}$ & $\mathbf{R}_{4}$ \\
\hline 11 & Centre & 208 & 95 & 1.0 & 2.957 & 18.632 & 16.595 & 1.10 \\
\hline 7 & Factorial & 206 & 98 & 1.2 & 2.812 & 14.566 & 12.989 & 1.00 \\
\hline 3 & Factorial & 206 & 98 & 0.8 & 3.119 & 21.207 & 18.930 & 1.42 \\
\hline 1 & Factorial & 206 & 92 & 0.8 & 3.282 & 22.802 & 20.291 & 1.53 \\
\hline 12 & Centre & 208 & 95 & 1.0 & 2.899 & 18.453 & 16.435 & 1.00 \\
\hline 4 & Factorial & 210 & 98 & 0.8 & 2.830 & 21.200 & 18.930 & 0.85 \\
\hline 5 & Factorial & 206 & 92 & 1.2 & 2.971 & 15.335 & 13.654 & 1.04 \\
\hline 2 & Factorial & 210 & 92 & 0.8 & 3.257 & 22.784 & 20.293 & 0.97 \\
\hline 8 & Factorial & 210 & 98 & 1.2 & 2.827 & 14.569 & 12.989 & 0.63 \\
\hline 9 & Centre & 208 & 95 & 1.0 & 2.891 & 18.305 & 16.318 & 1.01 \\
\hline 6 & Factorial & 210 & 92 & 1.2 & 2.986 & 15.335 & 13.654 & 0.66 \\
\hline 10 & Centre & 208 & 95 & 1.0 & 2.891 & 18.245 & 16.255 & 0.99 \\
\hline 14 & Axial & 210 & 95 & 1.0 & 2.954 & 18.631 & 16.593 & 0.76 \\
\hline 18 & Axial & 208 & 95 & 1.2 & 2.833 & 14.793 & 13.197 & 0.93 \\
\hline 15 & Axial & 208 & 92 & 1.0 & 3.126 & 18.315 & 16.314 & 1.04 \\
\hline 17 & Axial & 208 & 95 & 0.8 & 3.121 & 21.746 & 19.428 & 1.31 \\
\hline 13 & Axial & 206 & 95 & 1.0 & 2.938 & 18.617 & 16.591 & 1.18 \\
\hline 19 & Centre & 208 & 95 & 1.0 & 2.868 & 18.202 & 16.220 & 1.00 \\
\hline 20 & Centre & 208 & 95 & 1.0 & 2.855 & 18.180 & 16.206 & 0.99 \\
\hline 16 & Axial & 208 & 98 & 1.0 & 2.978 & 17.258 & 15.400 & 1.01 \\
\hline
\end{tabular}

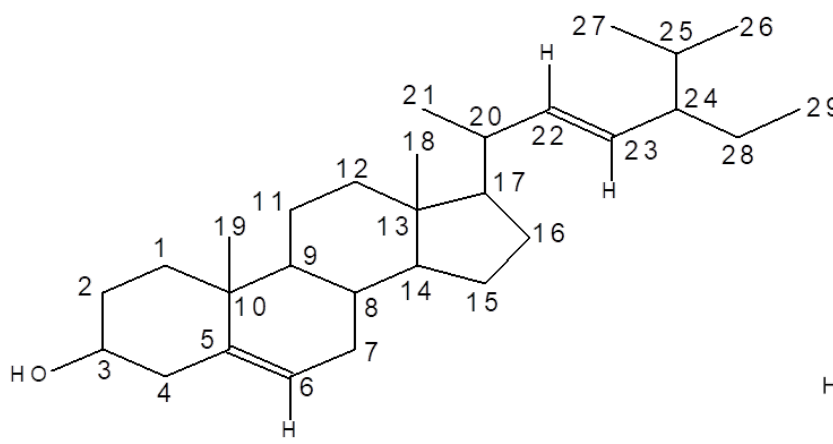

Stigmasterol

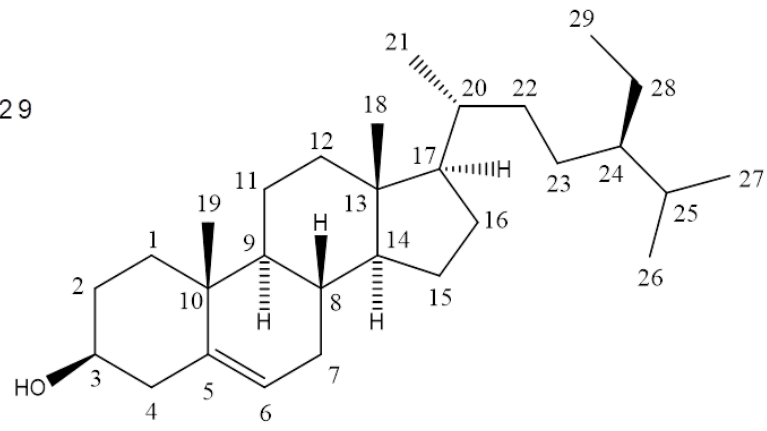

$\beta-S i t o s t e r o l$

Fig. 1: Chemical structures of stigmasterol and $\beta$-sitosterol.

All the analytical factors were done in randomized order to reduce the upshots of unbridled bias in all the variables which causes bias in the measurement of the responses. (Giriraj et al., 2014). The standard experimental error was estimated by selecting the replicates of central axis points. The experimental design for factorial analysis includes linear, quadratic and cross terms can be expressed as

$$
\mathrm{Y}=\beta_{0}+\beta_{1} \mathrm{X}_{1}+\beta_{2} \mathrm{X}_{2}+\beta_{3} \mathrm{X}_{3}+\beta_{12} \mathrm{X}_{1} \mathrm{X}_{2}+\beta_{13} \mathrm{X}_{1} \mathrm{X}_{3}+
$$

$$
\beta_{23} \mathrm{X}_{2} \mathrm{X}_{3}+\beta_{11} \mathrm{X}_{21}+\beta_{22} \mathrm{X}_{22}+\beta_{33} \mathrm{X}_{23} \text {, }
$$

where $\mathrm{Y}$ is the response to be modeled, $\beta$ is the regression coefficient and $\mathrm{X} 1, \mathrm{X} 2$, and $\mathrm{X} 3$ represents factors $\mathrm{A}, \mathrm{B}$, and $\mathrm{C}$ respectively.

The factors and the selected responses were analyzed using a "standard least squares" model. Calculated coefficients for the response model and the $\mathrm{P}(<0.05)$ were tabulated in Table 2 and for the coefficients of $\mathrm{P}>0.05$ were effused from the model using 
"backward elimination process" to gain a sensible and rational model (Kalariya et al., 2017). The adjusted $\mathrm{R}^{2} \geq 0.80$ reveals the experimental data exhibited a good fit with the second-order polynomial equations (Janardhanan et al., 2016). The reduced models after backward elimination orienting the factorial analysis with a $p$-value $<0.05$, were implied as significant. The adequate precision values were in the assortment of 11.28-108.93, indicates the adequacy of the model as eloquent. The $\% \mathrm{CV}$ for the factorial models was found to be $<5 \%$ indicates the fidelity of the method (Kuhnt et al., 2013; Xiao et al., 2015).

Table 2: Reduced response model ${ }^{\text {a }}$ (backward elimination process).

\begin{tabular}{cc}
\hline Response & Regression Model \\
\hline $\mathrm{R}_{1}$ & $2.91-0.105 \mathrm{~B}-0.118 \mathrm{C}-0.0996 \mathrm{~B}_{2}$ \\
$\mathrm{R}_{2}$ & $16.31-0.496 \mathrm{~B}-3.138 \mathrm{C}+0.174 \mathrm{BC}+0.361 \mathrm{~A}^{2}-0.373 \mathrm{~B}^{2}$ \\
$\mathrm{R}_{3}$ & $18.30-0.577 \mathrm{~B}-3.514 \mathrm{C}+0.205 \mathrm{BC}+0.420 \mathrm{~A}^{2}-0.417 \mathrm{~B}^{2}$ \\
$\mathrm{R}_{4}$ & $1.01-0.23 \mathrm{~A}-0.033 \mathrm{~B}-0.182 \mathrm{C}+0.047 \mathrm{AC}+0.02 \mathrm{BC}-0.0626 \mathrm{~A}^{2}+0.087 \mathrm{C}^{2}$ \\
\hline
\end{tabular}

anly significant coefficients with $\mathrm{P}<0.05$ are included. Factors are in coded levels.

The affirmative interaction between $\mathrm{B}$ and $\mathrm{C}$ was "eloquent and statistically significant" with the $\mathrm{P}<0.004$ for response $\mathrm{R}_{3}$ indicates a change in $\mathrm{MeOH}$ concentration from nadir to high results shows a marginal decline in the elution time of $\beta$-sitosterol either at the increasing or by decreasing the flow rate. On the later stage at a higher level of factor $\mathrm{C}$, rapid dwindling of the retention time was observed inferred that the foster interaction with largest absolute coefficient $\mathrm{B}$ and $\mathrm{C}$ among the fitted model was 0.205 . The utilization of all the variable interactions emphasizes the necessity to carry out active multifactor experiments for optimization of the chromatographic behavior of the analytes.

The predicted models presented in Fig. 2 as the perturbation plot (Decaestecker et al., 2004) explains better about the optimization of the chromatographic nature by depicting the "change in response to the particular factor which gets mobilized from the selected reference point, where the other factors were kept constant at the reference value". Higher the sensitivity of the response towards the factor, steeper is the slope. Based on the interpretations from the perturbation plots it was evident that factor $\mathrm{C}$ mostly affected the elution time $\left(\mathrm{R}_{3}\right)$, followed by factor $\mathrm{B}$ and $\mathrm{A}$. Hence of all responses, $\mathrm{R}_{3}$ was highly sensitized by the factorial design analysis and the perturbation plot was examined for the better understanding of the independent factors on a peculiar response (Hatambeygi et al., 2011).

\section{Derringer's desirability function}

Derringer's desirability function was used for the further optimization of responses using different factors. The Derringer's desirability function $\mathrm{D}$ is defined as the geometric mean, weighed or otherwise, of the individual desirability functions (Derringer et al., 1980). Desirability function scales the response of $0-1$. On the scale of 0 indicates an undesirable and 1 the most desirable response. The optimum conditions for the method were chosen based on the desirability value nearer to 1 . At the wavelength of $207.386 \mathrm{~nm}, \mathrm{MeOH}-93.314(\% \mathrm{v} / \mathrm{v})$ and flow rate of 0.948 $\mathrm{mL} \mathrm{min}^{-1}$, the maximum desirability of 0.967 was obtained within a difference of $<4 \%$ (Costa et al., 2011), stipulates a good correlation between the predicted and the experimental responses. The desirability graph was depicted in Fig. 3.

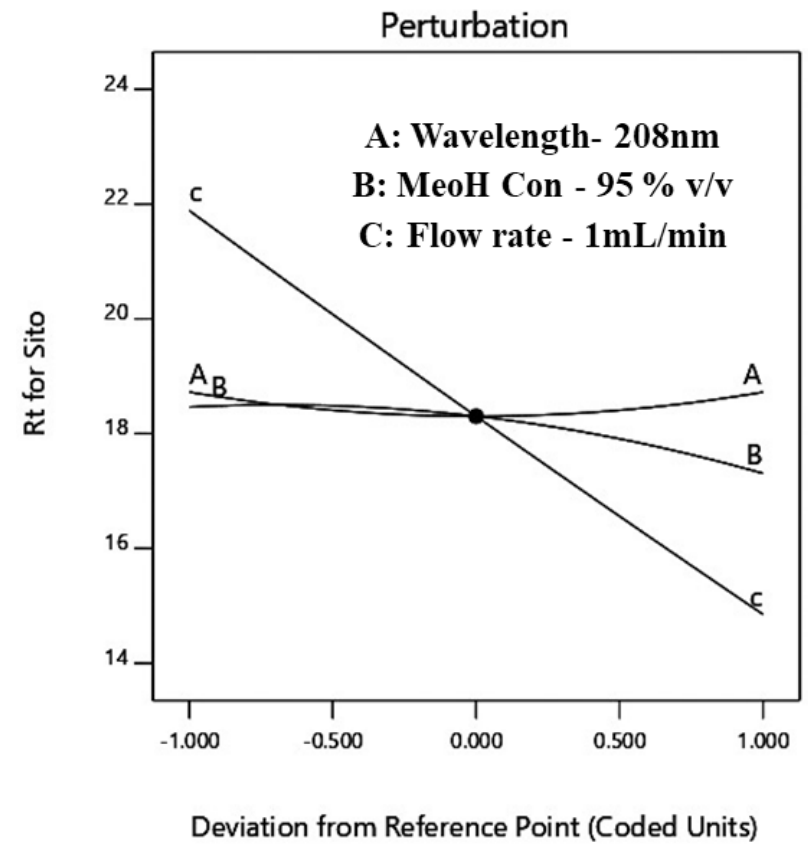

Fig. 2: Perturbation plot showing the effect of the independent variables on response $\mathrm{R}_{3}$ by keeping other variables constant.

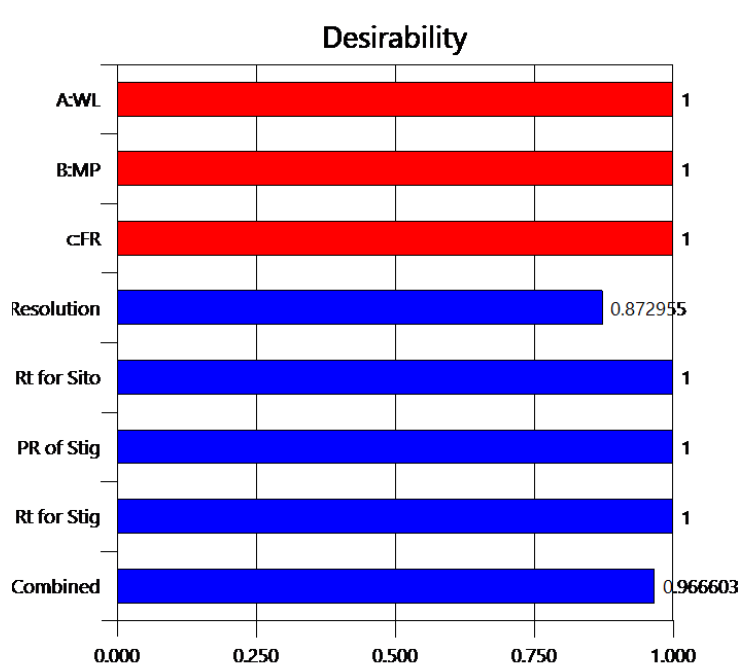

Fig. 3: Derringer's Desirability functions for the factors and responses.

\section{Response surface plots}

The optimization conditions for the factors selected and the responses were obtained by the regression equation (Tian et al., 2017). The three-dimensional response surface figures were attained using Design-Expert 11.0 version. The influence on the retention time of $\beta$-sitosterol by the variation of independent variables like wavelength, $\mathrm{MeOH}$ concentration and flow rate was displayed in Fig. 4a. In the response surface figures, response $\mathrm{R}_{3}$ was by amased using the 2 continuous variables where the other variable was kept constant. All the factors that are responsible for the change in response $\mathrm{R}_{3}$ were predicted at the confidence level of $95 \%$ confidence limit and represented in Fig. $4 \mathrm{a}$. 

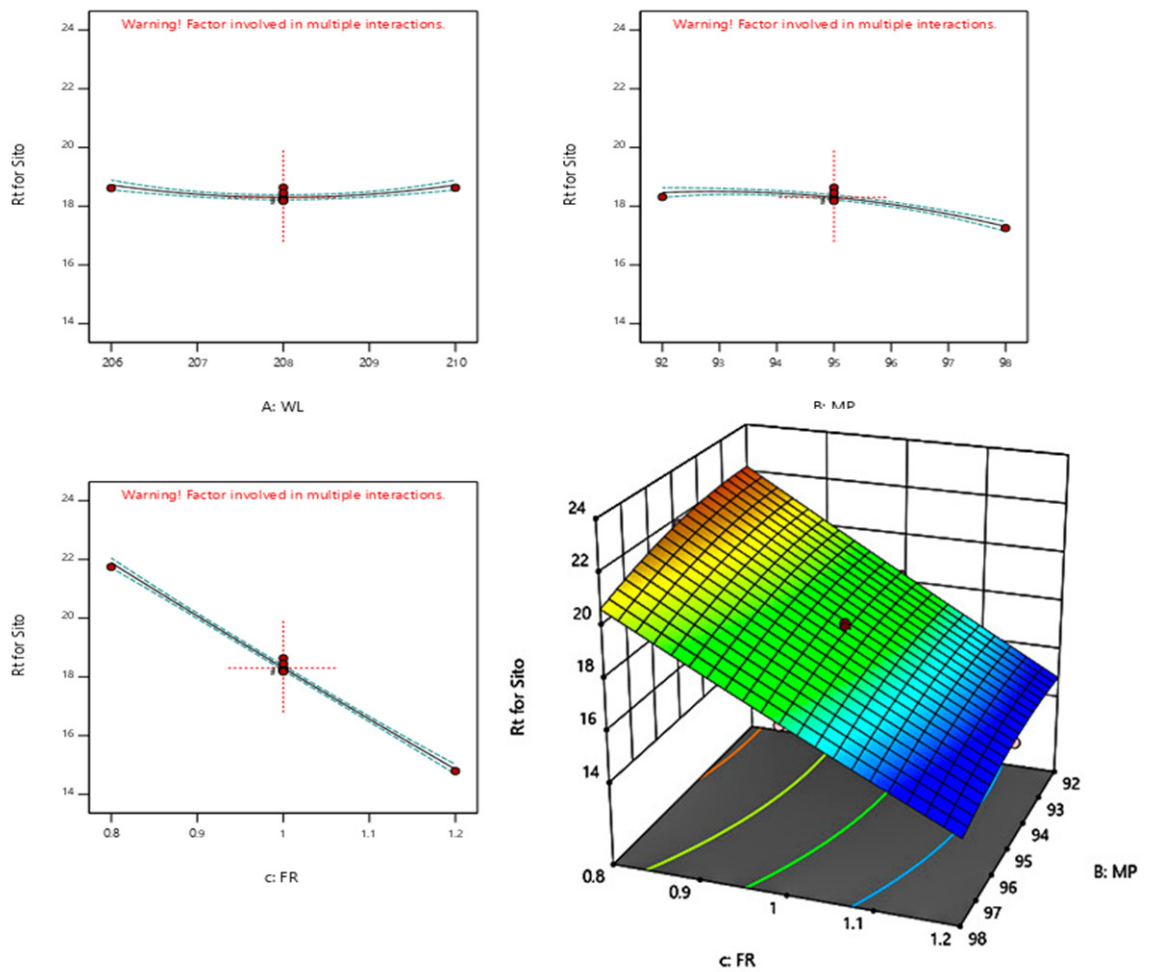

(a)
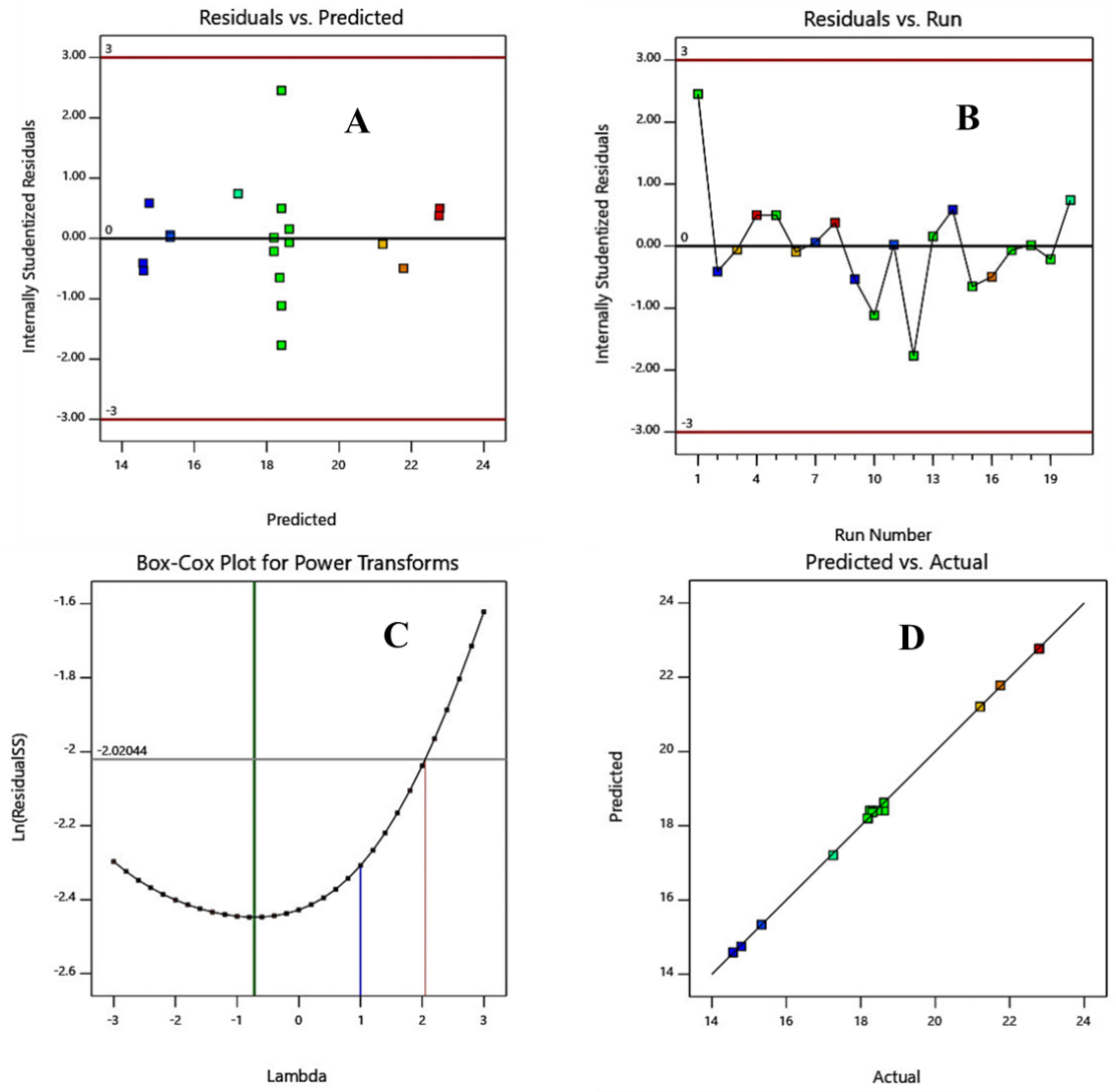

(b)

Fig. 4: a. Diagnostic plots and response surface plots for model adequacy. b. Residual plots and box-cox plot for the model. 


\section{Model adequacy diagnostics}

The applicability of the experimental model was diagnosed using Model adequacy test (Tahmouzi, 2014). The diagnostic figures for model adequacy were depicted in Fig. 4a. The Figs. 4b (A-D), shows all the diagnostic measures of the model which explains residual and predicted values. The internally studentized residuals versus predicted values were displayed in Fig. 4b (A). The consistency of all the values was interpreted from internally studentized residuals (Thangam et al., 2014). The experimental run numbers versus internally studentized residuals were shown in Fig. 4a (B). The lambda value of Box-cox plot for power transforms shows 0.72 , which implies the existing prediction model was fit and significant and no other Box-Cox transformation was recommended Fig. 4b (C).

\section{Method validation}

As per ICH Q2b validation guidelines, the developed RP HPLC method was validated for the parameters like linearity, specificity, LOD, LOQ, accuracy, precision, and robustness were performed (ICH, 2005).

\section{Linearity}

The stock solution with the concentration range of $80-130 \mu \mathrm{g} / \mathrm{mL}$ for stigmasterol and $\beta$-sitosterol respectively was selected for the calibration curve in the range of $100 \%$ with a deviation of $\pm 20 \%$ in the standard concentration used for accuracy and was analyzed in triplicate. Concentration and peak area were plotted to obtain least square regression analysis and to calculate regression equation. The regression coefficient $\left(r^{2}\right)$ was found to be 0.9971 and 0.9966 eliciting the linear response over the range and was represented in Fig. 5 and depicted in Table 3.

Table 3: Statistical parameters obtained from ANOVA.

\begin{tabular}{ccccc}
\hline Response & Adjusted $\mathbf{R}^{2}$ & Model P value & \% CV & Adequate Precision \\
\hline $\mathrm{R}_{1}$ & 0.8279 & 0.0008 & 2.01 & 11.2881 \\
$\mathrm{R}_{2}$ & 0.9984 & 0.0001 & 0.57 & 105.07 \\
$\mathrm{R}_{3}$ & 0.9986 & 0.0001 & 0.55 & 108.9307 \\
$\mathrm{R}_{4}$ & 0.9900 & 0.0001 & 2.23 & 53.0604 \\
\hline
\end{tabular}

\section{LOD and LOQ}

A calibration curve was constituted in the range of $80-130 \mu \mathrm{g} / \mathrm{mL}$ from the nominal analyte concentration. The LOD and LOQ were calculated from the regression equation of the calibration with the formula of LOD as $3.3 \mathrm{\sigma} / \mathrm{s}$ and LOQ as $10 \mathrm{\sigma} / \mathrm{s}$. Based on the given formula, the LOD and LOQ were calculated and were found to be $6.951,21.063 \mu \mathrm{g} / \mathrm{mL}$ and $6.048,18.328 \mu \mathrm{g} /$ $\mathrm{mL}$ of stigmasterol and $\beta$-sitosterol respectively.

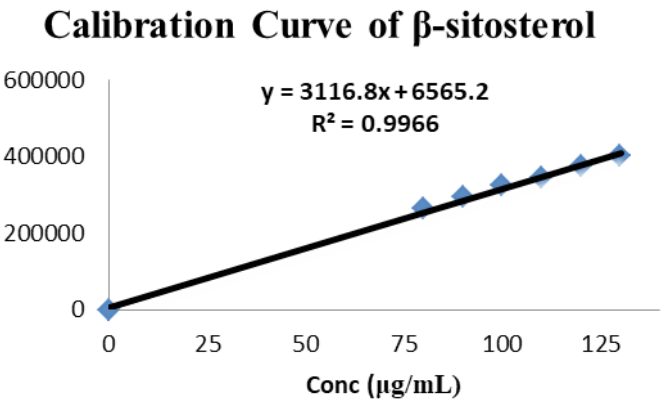

Fig. 5: Calibration curve of stigmasterol and $\beta$-sitosterol.

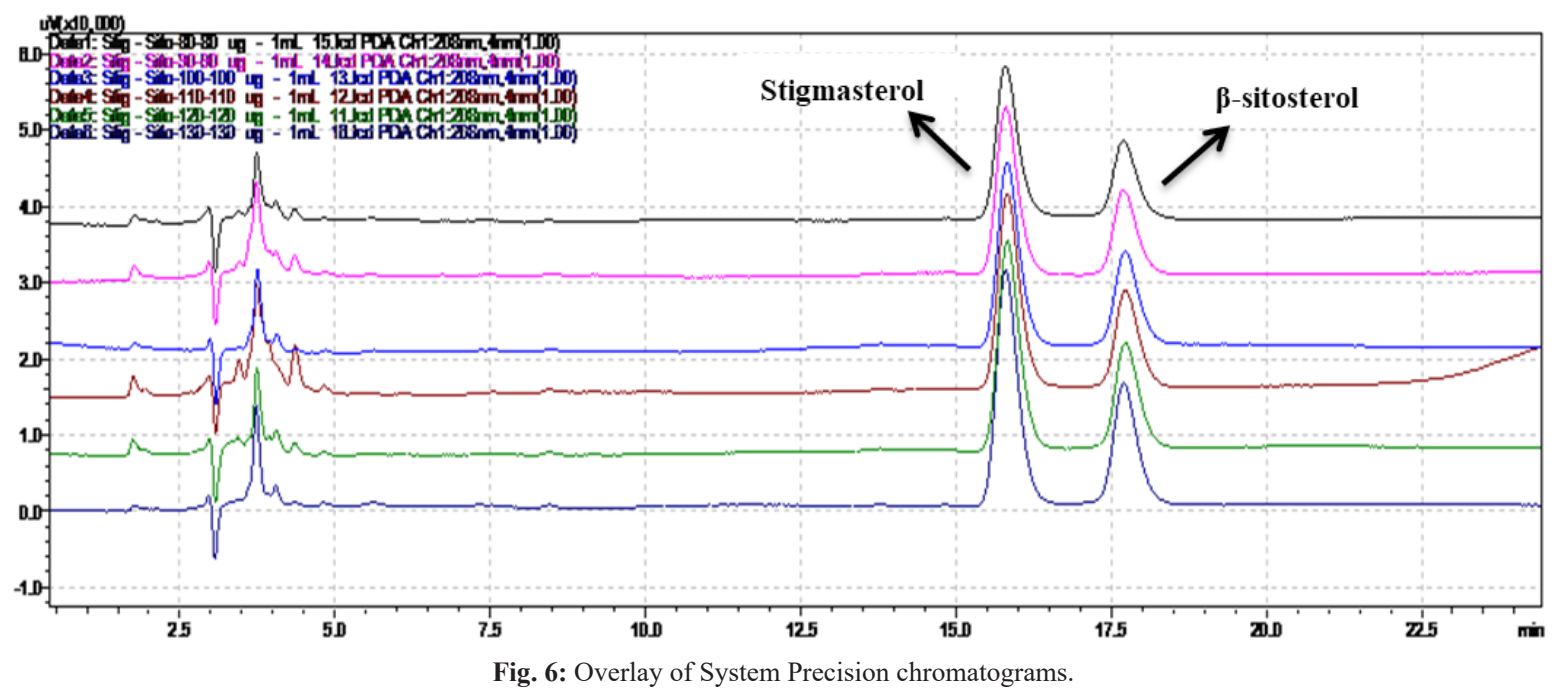




\section{Precision}

The method repeatability was calculated in terms of \% RSD using six replicates at $100 \%$ concentration of the standards for the determination of both intraday and interday precision. The data was reported in Tables $4 \& 5$ shown in Fig. 6. \% RSD NMT 2 specifies the repeatability and reproducibility of the developed method.

Table 4: Linearity, precision, accuracy and assay data of stigmasterol and $\beta$-sitosterol.

\begin{tabular}{|c|c|c|c|}
\hline \multicolumn{4}{|c|}{ Validation data of stigmasterol and $\beta$-sitosterol } \\
\hline & Parameters & Stigmasterol & $\beta$-sitosterol \\
\hline \multirow{3}{*}{$\begin{array}{l}\text { Linearity }(\mathrm{n}=3) \\
80-130 \mu \mathrm{g} / \mathrm{mL}\end{array}$} & Regression equation & $Y=22826 x-51498$ & $Y=21669 x-90599$ \\
\hline & Standard Error of Slope & 0.00017 & 0.00032 \\
\hline & Standard Error of Intercept & 1.5652 & 1.7908 \\
\hline \multirow[t]{3}{*}{ Accuracy $(\mathrm{n}=3)$} & 80 & $100.9 \pm 0.68$ & $100.1 \pm 0.93$ \\
\hline & 100 & $98.3 \pm 0.37$ & $100.9 \pm 0.97$ \\
\hline & 120 & $99.8 \pm 0.64$ & $102.4 \pm 0.49$ \\
\hline \multicolumn{4}{|c|}{ Precision $(\mathrm{n}=6)$} \\
\hline
\end{tabular}

Table 5: Intraday and interday precision data of stigmasterol and $\beta$-sitosterol.

\begin{tabular}{|c|c|c|c|c|c|c|c|}
\hline \multicolumn{4}{|c|}{ Stigmasterol $(n=6)$} & \multicolumn{4}{|c|}{$\beta$-sitosterol $(n=6)$} \\
\hline \multicolumn{2}{|c|}{ Intraday } & \multicolumn{2}{|c|}{ Interday } & \multicolumn{2}{|c|}{ Intraday } & \multicolumn{2}{|c|}{ Interday } \\
\hline 16.595 & 653052 & 16.692 & 635502 & 18.632 & 344085 & 18.457 & 358404 \\
\hline 16.318 & 654240 & 16.324 & 642405 & 18.305 & 341937 & 18.264 & 343912 \\
\hline 16.255 & 642429 & 16.547 & 652059 & 18.242 & 340983 & 18.658 & 343890 \\
\hline 16.209 & 638781 & 16.121 & 648378 & 18.180 & 349914 & 18.438 & 349419 \\
\hline 0.92 & 0.94 & 1.22 & 0.98 & 0.96 & 1.51 & 1.00 & 1.83 \\
\hline
\end{tabular}
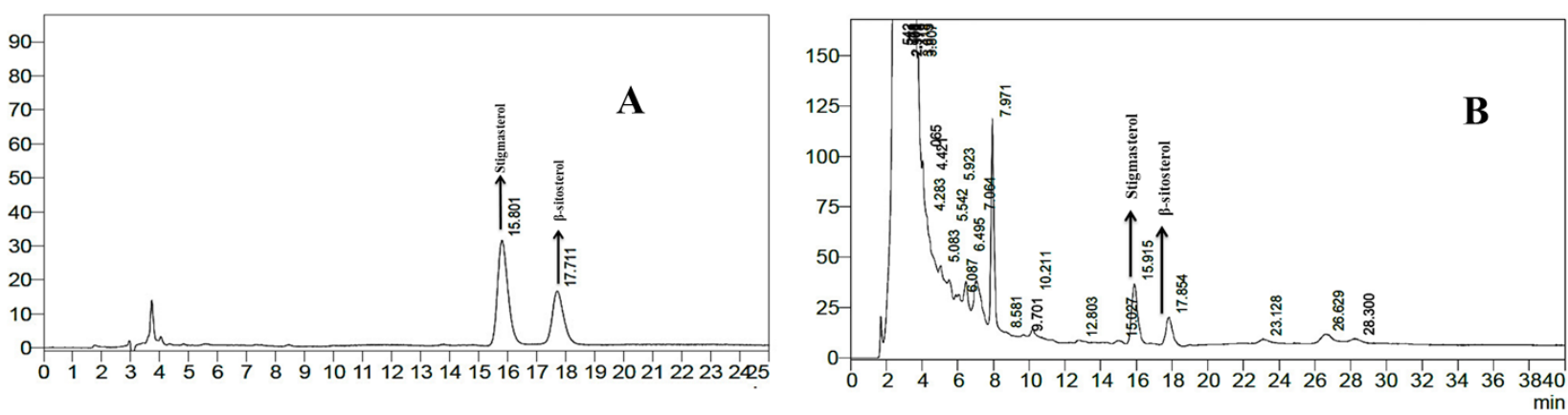

Fig. 7: Chromatogram of stigmasterol and $\beta$-sitosterol in standard and MMV.

\section{Accuracy}

To ensure the consistency and accuracy of the method, the standard addition method was followed to perform the recovery studies by spiking the unknown concentration of the standards spiked at $100 \pm 20 \%$ level of the nominal concentration of the test solution of 51.0 and $56.3 \mu \mathrm{g} / \mathrm{mg}$ of stigmasterol and $\beta$-sitosterol respectively. Triplicate analysis of the study at each level was studied; the standard and the sample chromatograms were represented in Fig. 7 and tabulated in Table 4. 


\section{Robustness}

To perform the robustness of the study, all the independent variables like mobile phase, wavelength, and flow were premeditatedly studied to identify the influence of the independent factors on the proposed method. With the change in flow rate, mobile phase there is a significant change in the elution time and no alteration of the qualitative parameter with the change in wavelength.

Appendix A: Robustness data of Stigmasterol and $\beta$-sitosterol.

\begin{tabular}{|c|c|c|c|c|c|c|c|}
\hline Chemical Marker & Parametres & Change & Rt (min) & $\mathrm{K}^{\prime}$ & ASF & $\mathbf{R}_{\mathrm{s}}$ & Plate number \\
\hline \multicolumn{8}{|c|}{ Nominal Concentration } \\
\hline Stigmasterol & -- & -- & 16.220 & 4.561 & 1.178 & NA & 9589 \\
\hline$\beta$-sitosterol & -- & -- & 18.202 & 2.786 & 1.128 & 2.868 & 10247 \\
\hline \multirow{2}{*}{ Stigmasterol } & \multirow{4}{*}{ Mobile Phase A } & Low (92) & 16.314 & 4.027 & 1.150 & NA & 11385 \\
\hline & & High (98) & 15.400 & 2.516 & 1.179 & NA & 10546 \\
\hline \multirow{2}{*}{$\beta$-sitosterol } & & Low (92) & 18.315 & 4.219 & 1.164 & 3.126 & 12016 \\
\hline & & High (98) & 17.258 & 2.373 & 1.137 & 2.978 & 11355 \\
\hline Stigmasterol & \multirow{4}{*}{$\begin{array}{l}\text { Flow rate } \\
\left.(\mathrm{ml} \mathrm{min})^{-1}\right)\end{array}$} & Low $(0.8)$ & 19.426 & 4.322 & 1.146 & NA & 11640 \\
\hline \multirow{3}{*}{$\beta$-sitosterol } & & High (1.2) & 13.197 & 2.638 & 1.192 & NA & 9560 \\
\hline & & Low $(0.8)$ & 21.746 & 4.481 & 1.104 & 3.121 & 12878 \\
\hline & & High (1.2) & 14.793 & 2.814 & 1.183 & 2.833 & 10155 \\
\hline \multirow[t]{2}{*}{ Stigmasterol } & & Low (206) & 16.591 & 4.751 & 1.160 & NA & 9941 \\
\hline & Whenton & High (210) & 16.593 & 2.552 & 1.158 & NA & 9912 \\
\hline \multirow[t]{2}{*}{$\beta$-sitosterol } & waverengm & Low (206) & 18.617 & 4.490 & 1.203 & 2.938 & 10878 \\
\hline & & High (210) & 18.631 & 2.625 & 1.153 & 2.954 & 10934 \\
\hline
\end{tabular}

Where Rt: Retention time, K': Capacity factor, ASF: Tailing factor, $\mathrm{R}_{\mathrm{s}}$ : Resolution, Plate number: Theoretical Plate number.

The symmetrical parameters like theoretical plate number, capacity factor were significant and tabulated within the limits and were depicted in Table 6. From the results obtained, it implies the method was robust with the change in chromatographic parameters.

Table 6: System suitability parameters of stigmasterol and $\beta$-sitosterol.

\begin{tabular}{cccc}
\hline SST Parameters & Stigmasterol $(\mathrm{n}=\mathbf{6})$ & $\boldsymbol{\beta}$-sitosterol $(\mathbf{n}=\mathbf{6})$ & Limits \\
\hline Resolution & NA & 2.89 & $\geq 2$ \\
Asymmetric Factor & 1.16 & 1.143 & $\leq 2$ \\
Capacity Factor & 4.49 & 2.86 & $\geq 2$ \\
\# Theoretical Plates & 9679 & 10493 & $\geq 2000$ \\
\hline
\end{tabular}

\section{DISCUSSION}

For the simultaneous estimation of stigmasterol and $\beta$-sitosterol, application of chemometrics evince to be a significant approach in optimizing the selectivity of the independent variables. The significant factors were optimized by response surface methodology, central composite design and model adequacy diagnosis explains about the extent of application for the experimental model. The elution and the runtime for the elutes were diagnosed both qualitatively and quantitatively using the derringers $\mathrm{D}$ value and the perturbation plots. The CCD provides the better insight into the prior and proper understanding of the chromatographic behavior, the sensitivity of the independent variables in the process of chromatographic separation. Of all the factors used in the design, "factor $\mathrm{C}$ was shown highly affecting the experimental method as per the CCD results, in which six replicates were taken as central and axial points, 14 factorial points" as a datum for the prediction of the results.

\section{CONCLUSION}

The developed method is the first report for the simultaneous estimation of stigmasterol and $\beta$-sitosterol in Manasamitra Vatakam. In the present study, a simple, efficient, precise and accurate RP-HPLC method was optimized and validated for the simultaneous estimation of the Stigmasterol and $\beta$-sitosterol respectively. Highly sensible method, reducing the chromatographic run time, economic usage of chromatographic solvents, the adequate resolution between the two elutes emphasize that the developed method was qualitatively and quantitatively determined and demonstrates the necessity of the method to further contemplate for the future analytical applications. The developed HPLC method was found to be sensitive, simple, linear, precise, selective and accurate. Hence, the method can be successfully adopted for "conventional qualitative and quantitative analysis of stigmasterol and $\beta$-sitosterol in ayurvedic formulations".

\section{ACKNOWLEDGMENTS}

The authors are highly grateful to SRM Institute of Science and technology for providing the facilities and infrastructure for the study.

\section{CONFLICTS OF INTEREST}

None of the authors declare a conflict of interest.

\section{REFERENCES}

Pande PP, Sayyad SF, Chavan MJ, Chaudhari SR. Quality by design in analytical method development and validation. J Environ Life Sci, 2017; 2:39-45.

Sivakumar T, Manavalan R, Muralidharan C, Valliappan K. An improved HPLC method with the aid of a chemometric protocol: Simultaneous analysis of amlodipine and atorvastatin in pharmaceutical 
formulations. J Sep Sci, 2007; 30:3143-3153.

Mannemala SS, Valliappan K. Multiple response optimization of a liquid chromatographic method for determination of fluoroquinolone and nitroimidazole antimicrobials in serum and urine. Clin Biochem, 2016; 49:587-595.

Sivakumar T, Manavalan R, Muralidharan C, Valliappan K. Multi-criteria decision-making approach and experimental design as chemometric tools to optimize HPLC separation of domperidone and pantoprazole. J Pharm Biomed Anal, 2007; 43:1842-1848.

Benzie IFF, Wachtel-Galor S. 2011. Herbal Medicine: Biomolecular and Clinical Aspects, Second Edition, CRC Press. http:// www.crcpress.com/.

Sahoo N, Manchikanti P, Dey S. Herbal drugs: Standards and regulation. Fitoterapia, 2010; 81:462-471.

Shri PR. Krishna Kumar J. 2008. Sahasrayogam. Chowkamba Krishnadas Academy, Chowkamba Press.

Goldberg EM, Coulter DA. Mechanisms of epileptogenesis: a convergence on neural circuit dysfunction. Nat Rev Neurosc, 2013; 14:337349 .

Thirunavukkarasu SV, Jayanthi M, Raja S, Venkataraman S. Effect of Manasamitra vatakam against aluminium induced learning and memory impairment of apoptosis in rat's hippocampus and cortex. J Drug Metab Toxicol, 2013; 4:1-11.

Naiyer S, Wajahatullah K, Shadab MD, Asgar A, Sundeep SS, Sadhana S, Faisal A, Zainularifeen A, Ibrahim A, Abdel-WA, Mohamed A, Al-Ghamdi SS. Phytosterols as a natural anticancer agent: Current status and future perspective. Biomed Pharmacother, 2017; 88:786-794.

Scholz B, Guth S, Engel KH, Steinberg P. Phytosterol oxidation products in enriched foods: occurrence, exposure, and biological effects, Mol Nutr Food Res, 2015; 59:1339-1352.

Sandhiya S, Ganesh MR, Mohan R Dubey GP. Identification of beta-sitosterol and stigmasterol in Bambusa bambos (L.) Voss leaf extract using HPLC and its estrogenic effect in vitro. J Pharm Biomed Anal, 2015; 115:55-61.

Nair VDP, Kanfer I, Hoogmartens J. Determination of stigmasterol, $\beta$-sitosterol and stigmastanol in oral dosage forms using high performance liquid chromatography with evaporative light scattering detection. J Pharm Biomed Anal, 2006; 41:731-737.

Careri M, Elviri L, Mangia A. Liquid chromatography-UV determination and liquid chromatography-atmospheric pressure chemical ionization mass spectrometric characterization of sitosterol and stigmasterol in soyabean oil. J Chromatogr A, 2001; 935:249-257.

Anjoo K, Ajay KS. Development of validated HPTLC method for quantification of stigmasterol from leaf and stem of Bryophyllum pinnatum. Arab J Chem, 2017; 10:55-61.

Bezerra MA, Santelli RE, Oliveira EP, Villar LS, Escaleira LA. Response surface methodology (RSM) as a tool for optimization in analytical chemistry. Talanta, 2008; 76:965-977.

Wang Y, Harrison M, Clark BJ. Optimising reversed-phase liquid chromatographic separation of an acidic mixture on a monolithic stationary phase with the aid of response surface methodology and experimental design. J Chromatogr A, 2006; 11:199-207.

Sivakumar T, Manavalan R, Valliappan K. Global optimization using derringer's desirability function: enantioselective determination of ketoprofen in formulations and in biological matrices. Acta Chromatogr, 2007; 19:29-47.

Giriraj P, Sivakkumar T. Development and Validation of a Rapid
Chemometrics Assisted RP-HPLC with PDA Detection Method for the Simultaneous Estimation of Pyridoxine $\mathrm{HCl}$ and Doxylamine Succinate in Bulk and Pharmaceutical Dosage Form, Chromatography Research International. 2014.

Kalariya PD, Namdev D, Srinivas R, Gananadhamu S. Application of experimental design and response surface technique for selecting the optimum RP-HPLC conditions for the determination of moxifloxacin $\mathrm{HCl}$ and ketorolac tromethamine in eye drops. J Saudi Chem Soc, 2017 ; 21:373-382

Janardhanan VS, Manavalan R, Valliappan K. Chemometric technique for the optimization of chromatographic system: Simultaneous HPLC determination of Rosuvastatin, Telmisartan, Ezetimibe and Atorvastatin used in combined cardiovascular therapy. Arab J Chem, 2016; 9:1378-1387.

Kuhnt S, Rudak N. Simultaneous Optimization of Multiple Responses with the R Package JOP. J Stat Softw, 2013; 54:1-23.

Xiao YZ, Wu DK, Zhao SY, Lin MW, Gao XY. Statistical Optimization of Alkaline Protease Production from Penicillium citrinum YL-1 Under Solid-State Fermentation. Prep Biochem Biotechnol, 2015; 45:447-462.

Decaestecker TN, Lambert WE, Peteghem VCH, Deforce D, Bocxlaer VJF. Optimization of solid-phase extraction for a liquid chromatographic-tandem mass spectrometric general unknown screening procedure by means of computational techniques. J Chromatogr A, 2004; 1056:57-65.

Hatambeygi N, Abedi G, Talebi M. Method development and validation for optimised separation of salicylic, acetyl salicylic and ascorbic acid in pharmaceutical formulations by hydrophilic interaction chromatography and response surface methodology. J Chromatogr A, 2011; 1218:5995-6003.

Derringer G, Suich R, Simultaneous optimization of several response variables. J Qual Technol, 1980; 12:14-219.

Costa NR, Lourenço J, Pereira ZL. Desirability function approach: A review and performance evaluation in adverse conditions Chemom Intell Lab Syst, 2011; 107:234-244.

Tian S, Hao C, Xu G, Yang J, Sun R. Optimization conditions for extracting polysaccharide from Angelica sinensis and its antioxidant activities. J Food Drug Anal, 2017; 25:766-775.

Tahmouzi S. Optimization of polysaccharides from Zagros oak leaf using RSM: Antioxidant and antimicrobial activities. Carbohydr Polym, 2014; 106:238-246.

Thangam R, Suresh V, Kannan S. Optimized extraction of polysaccharides from Cymbopogon citratus and its biological activities. Int J Biol Macromol, 2014; 65:15-23.

International Conference on Harmonization of Technical Requirements for Registration of Pharmaceutical for Human Use ICH Guidelines. Validation of analytical procedures text and methodology Q2B (R1), 2005.

How to cite this article:

Vemuri S, Ramasamy MK, Rajakanu P, Kumar RCS, Kalliappan I. Application of Chemometrics for the simultaneous estimation of stigmasterol and $\beta$-sitosterol in Manasamitra Vatakam-an ayurvedic herbomineral formulation using HPLC-PDA method. J App Pharm Sci, 2018; 8(07): 001-009. 